\title{
СЕГМЕНТНЫЙ ПОДХОД К КАДРОВОМУ ЯДРУ ОРГАНИЗАЦИИ
}

\begin{abstract}
АНнотАЦия. В статье исследуется актуальная проблема выделения из кадрового состава организации кадрового ядра, а также установления внутренней структуры самого ядра. Для этого используется сегментный подход. Приведены сущность сегментного подхода и базовые его понятия - сегмент и сегментирование. Систематизируются и сопоставляются трактовки сегментного подхода в таких отраслях научных знаний, как маркетинг, рынок труда, управление персоналом. Это позволило адаптировать имеющиеся наработки данных отраслей к предметной области исследования - к структуре кадрового ядра. В частности, дается авторское определение сегментирования кадрового ядра, приводится перечень критериев или параметров сегментирования, перечисляются критерии, наиболее актуальные для сегментирования именно кадрового ядра. Далее делается вывод о том, что выбор критериев зависит от целей сегментировании, приводятся примеры целей и адекватных им критериев. Предлагается перечень направлений использования результатов сегментирования кадрового ядра. Главным направлением названа возможность выработки целевой дифференцированной кадровой политики в отношении разных сегментов кадрового ядра для повышения результативности выполняемых ядром функций. кЛючевЫЕ СЛОВА. Кадровое ядро; кадровый состав; егмент; сегментирование; структура кадрового ядра.

ИНФОРМАЦИЯ О СТАТЬЕ. Дата поступления 12 июля 2016 г.; дата принятия к печати 5 сентября 2016 г.; дата онлайн-размещения 30 сентября 2016 г.
\end{abstract}

G. V. Lyamin

F. M. Dostoevsky Omsk State University, Omsk, Russian Federation

\section{SEGMENTAL APPROACH TO HR-CORE OF AN ORGANIZATION}

ABSTRACT. The article investigates a topical problem of separating the HR-core from the personnel of the organization and establishing the internal structure of the core. To do this, the segmented approach is used. The article brings forth the essence of the segmented approach and its basic concepts of segment and segmentation. It systematizes and compares interpretation of the segmented approach in such sectors of scientific knowledge as marketing, labor market, personnel management. This allows to adapt the existing best practices of these industries to the subject area of the study - to the HR-core structure. In particular, the paper author gives the author's definition of the HR-core segmentation, provides a list of criteria or parameters of segmenting, specifies the criteria that are most relevant exactly for segmenting the HR-core. Further, it draws a conclusion that the choice of criteria depends on the goals of segmentation, gives examples of goals and adequate criteria. It offers a list of directions in using the results of the HR-core segmentation. The main direction is a possibility of developing a purposeful differentiated personnel policy for various segments of the HR-core in order to improve the efficiency performed by the core function.

KEYWORDS. HR-core; personnel; segment; segmentation, structure of HR-core.

ARTICLE INFO. Received July 12, 2016; accepted September 5, 2016; available online September 30, 2016.

Актуальной научной и прикладной проблемой, исследуемой автором данной работы, является то, что кадровое ядро в публикациях позиционируется как единое целое, не обладающее структурными элементами. Отчасти это справедливо, так как выделение кадрового ядра из всей совокупности кадрового состава орга-

(C) Г. В. Лямин, 2016

\section{Baikal Research Journal}


низации осуществляется с помощью поиска единых, объединяющих всех участников ядра качеств. Чаще таким качеством называют повышенную ценность кадрового ядра для организации по сравнению с остальным персоналом, который часто именуют «периферией» [1; 2]. Вместе с тем для выработки кадровой политики в отношении кадрового ядра, поиска наиболее эффективных методов его мотивации необходимо признать, что кадровое ядро также неоднородно по своему составу. В связи с чем возникает задача выяснения структуры кадрового ядра и обоснования разнообразных направлений работы с разными элементами ядра. Эта задача не решена в экономической науке и практике. Ее решению отчасти посвящено данное исследование, целью которого выступает адаптация сегментного подхода к установлению структуры кадрового ядра организации. На данном этапе используется методология теоретического системного анализа, в частности, методы систематизации, группировок, классификаций. На последующих этапах нашего исследования предполагается эмпирическое исследование на базе заложенных в данной части работы научных положений.

Обратимся к краткому обзору имеющихся наработок по предмету нашего исследования. В экономической науке используется понятие кадрового ядра. При этом под ним чаще понимают совокупность сотрудников, обладающих наибольшей ценностью для организации, которых требуется сохранять и в которых целесообразно вкладывать ресурсы ${ }^{1}$. Не отрицая правомерности такой интерпретации, автор данного исследования предлагает расширенную трактовку кадрового ядра. В частности, под кадровым ядром понимается команда единомышленников, которые активно, добровольно, на принципах саморегулирования и самоорганизации соучаствуют в управлении организацией, в выработке и реализации стратегии, в инновационной политике компании. Таким образом атрибуты отнесения к кадровому ядру расширяются, к ним в настоящее время можно отнести повышенную лояльность и приверженность компании, вовлеченность и мотивированность, установки на инновационность и позитивные изменения, соучастие в управлении организацией и оказание помощи управленческой команде, а зачастую и вхождение в состав команды управления организацией. Кадровое ядро как команда - это совокупность сотрудников, которые «разделяют цели, ценности и общие подходы к реализации совместной деятельности и взаимоопределяют принадлежность свою и партнеров к данной группе» [3, с. 134]. Отсутствие хотя бы одного из названных в определении признаков команды делает кадровое ядро неэффективным, следовательно, ненужным для организации.

Кадровое ядро представляет ценность не само по себе, а благодаря выполняемым им функциям, которые в процессе исследования автор данной статьи обобщил [4, с. 155-160] и отнес к ним следующие:

1. Функция инновационных изменений и поддержки организационной стратегии.

2. Функция формирования и упрочения корпоративной культуры, поддержания благоприятного социально-психологического климата.

3. Функция стабилизации и поддержки персонала.

4. Функция управления знаниями.

5. Функция участия в управлении.

6. Функция обеспечения самоорганизации и самоуправления.

7. Функция формирования единой макрокоманды организации.

8. Функция формирования особой сети коммуникаций и социально-трудовых отношений в организации.

${ }^{1}$ Положение о ключевых работниках организации [Электронный ресурc]. URL : http://www. jobgrade.ru/modules/Articles/article.php?storyid=1079.

\section{Baikal Research Journal}


9. Функция экономии ресурсов (временных, кадровых, информационных и др.).

10. Функции обеспечения брэнда и позитивного имиджа организации во внешней среде.

Изучая кадровое ядро организации, необходимо, прежде всего, признать его как элемент в кадровой структуре всей организации, т. е. кадровое ядро - это определенный сегмент в общей структуре кадров организации. Кроме того, само кадровое ядро неоднородно, оно состоит также из микро- и макрогрупп. Таким образом, автор выдвигает идею о том, что выделение и формирование кадрового ядра в целом и отдельных его компонентов должно происходить с помощью сегментного подхода. При этом применительно к кадровому составу организаций в незначительной степени используется сегментный подход и соответствующий ему метод сегментирования персонала, который в целом используется для облегчения оптимизации кадровых решений с учетом специфики разных групп кадров и для оптимизации состава персонала. По своей сути сегментный подход - это способ дифференцированного управления сотрудниками организации.

Сегментный подход как общенаучная методология представляет собой набор принципов, критериев и способов деления чего-либо на сегменты с последующим принятием различных решений в отношении разных сегментов или с учетом специфики разных сегментов. В разных науках и многих отраслях экономической науки сегментный подход используется в маркетинге, экономике труда, управлении персоналом, стратегическом менеджменте, антикризисном управлении и т. д.

Суть сегментного подхода к персоналу организаций состоит в делении всех сотрудников компании на определенное множество сегментов в зависимости от их ценности для организации и использовании в кадровом планировании и в целом в кадровой работе особенностей и значимости каждой группы. При этом критерий ценности может конкретизироваться с учетом целей сегментирования. Так, ценностью может считаться вклад в общую конкурентоспособность организации, в стратегию развития или антикризисную стратегию, в ключевые показатели эффективности и иные целевые ориентиры предприятия.

Приведем наиболее распространенные направления использования сегментного подхода в отношении кадров организации. Такой подход применяется, например, при выделении категорий, подлежащих сокращению в условиях кризиса, при определении соотношения внутреннего и внешнего привлечения персонала и т. д. Он эффективен и при планировании системы компенсации труда, в том числе при выработке политики социальных льгот и привилегий для разных групп персонала. На его основе целесообразно строить систему развития кадров и, прежде всего, резерв руководителей, а также планы по изменению состава персонала и его привлечению.

В целом можно сказать, что ответ на вопрос о том, для чего используется сегментирование персонала, зависит от стратегии организации. Признано, что соответствие стратегическим целям является одним из важнейших критериев при разделении сегментов, установлении их субординации и построении политики оптимизации кадрового состава.

Выделение сегментов может происходить по разным причинам. Первая группа причин - объективные. Деятельность учреждения всегда связана с наличием в его структуре групп, которые в этом случае создаются в результате естественных и объективных процессов организационного построения и организационной динамики. Вторая группа причин - субъективные. Это причины, связанные с необходимостью оптимального принятия управленческих решений, ориентированных на особенности сегментов. В последнем случае сегменты выделяются осознанно и под влиянием специальных усилий по сегментированию кадрового состава организации. В данном исследовании акцент сделан на второй группе причин. Сегментирование кадрового

\section{Baikal Research Journal}

электронный научный журнал Байкальского государственного университета 
ядра - это целенаправленный процесс деления всего ядра на группы для выработки и реализации сегментооориентированной кадровой политики в отношении ядра персонала организации. Однако при этом признается, что объективные причины сегментирования всегда проявляются и должны быть учтены в целенаправленном сегментировании кадрового ядра.

Обозначив в общих чертах сущность сегментного подхода, обратимся к более детальному анализу его основ и к их адаптации к рассматриваемому предмету исследования - кадровому ядру организации. Для начала обозначим понятия группы и сегмента, хотя в науке используются оба, так как по своей сущности они очень близки.

Группа - это совокупность двух и более человек, объединенных общей целью, интересами и деятельностью, т. е. критериями выделения группы выступают общие цель, интересы и деятельность. Как будет видно далее, сегменты тоже выделяются по признакам и часто к ним относятся указанные критерии, но они могут быть и иные. Поэтому применительно к сегментам понятие «группа» относится лишь отчасти.

Сегмент - часть чего-то, выделенная по определенным признакам. Сегментом называют совокупность людей, объединенную общим или похожим признаком, значимым для какой-то определенной цели. Например, сегменты по признаку уровня лояльности сотрудников каждого сегмента к организации с целью выработки программы повышения и удержания кадровой лояльности.

Часто данные понятия используют как синонимы. Например, при определении сегментирования применяют понятия сегмента и группы как синонимичные. Объединяющим эти понятия основанием является то, что участники групп и сегментов соединены общим(-ми) признаком(-ами) или аналогичными, схожими чертами. Далее будут представлены эти признаки. Однако на данном этапе сделаем вывод о том, что кадровое ядро само представляет собой сегмент и состоит из сегментов.

Сегмент кадрового ядра - это совокупность сотрудников, одинаковым образом реагирующих на проводимую организацией инновационную, антикризисную, кадровую политику, а также на побудительные воздействия со стороны организации, направленные на вовлечение персонала в разработку и реализацию стратегии. Эти реакции, в свою очередь, определяются различиями в потребностях, мышлении, мотивации, личностных качествах, квалификации и иных характеристиках. Поскольку таких критериев отнесения сотрудников к кадровому ядру множество, то именно по этим критериям и производится деление ядра на сегменты.

Выделение сегментов происходит с помощью сегментирования. При этом понятие сегментирования (сегментации) давно и успешно используется в маркетинге, экономике труда, управлении предприятием и его кадровым составом [5-8]. Представим сравнительный анализ существующих подходов к сущности сегментирования на основании изучения профильной литературы (табл.).

Как видно из данных (см. табл.), каждый подход трактует примерно одинаково сегментирование, внося лишь небольшие дополнения и пояснения, значимые для нашего исследования в части выработки сегментов кадрового ядра.

Рассмотрим сущность сегментирования более подробно в каждом подходе. Так, с позиций маркетингового подхода сегментация, во-первых, предполагает деление на сегменты, во-вторых, деление по схожим признакам, в-третьих, изучение реакции или поведения сегментов в отношении чего-либо, в-четвертых, выделение целевых сегментов для дифференцированной политики в отношении их. Данные составные части сущности сегментации будут нами использованы при выведении определения сегментации кадрового ядра.

\section{Baikal Research Journal}

электронный научный журнал Байкальского государственного университета 


\section{Сопоставительный анализ подходов к сеглентированию и возможности их использования применительно к кадроволу ядру организации}

\begin{tabular}{|c|c|c|c|}
\hline Подходы & Сущность подхода & $\begin{array}{c}\text { Преимущества } \\
\text { подхода }\end{array}$ & $\begin{array}{c}\text { Потенциал для использова- } \\
\text { ния применительно к сегмен- } \\
\text { тированию кадрового ядра }\end{array}$ \\
\hline Маркетинговый & $\begin{array}{l}\text { Деление покупателей } \\
\text { (клиентов) на сегменты } \\
\text { с одинаковыми ценно- } \\
\text { стями и иными характе- } \\
\text { ристиками с тем, чтобы } \\
\text { делать им ценностное } \\
\text { предложение }\end{array}$ & $\begin{array}{l}\text { Возможность устано- } \\
\text { вить разнородность } \\
\text { покупателей (кли- } \\
\text { ентов), выделить } \\
\text { ключевые сегменты, } \\
\text { отметить разные цен- } \\
\text { ностные предложения } \\
\text { и повысить продажи }\end{array}$ & $\begin{array}{l}\text { Выработанные принципы, } \\
\text { приемы, критерии сегменти- } \\
\text { рования, а также инструмен- } \\
\text { ты ценностных предложе- } \\
\text { ний можно адаптировать к } \\
\text { кадровому ядру }\end{array}$ \\
\hline $\begin{array}{l}\text { Экономический } \\
\text { (экономика } \\
\text { труда) }\end{array}$ & $\begin{array}{l}\text { Процесс разделения (в } \\
\text { рамках спроса на персо- } \\
\text { нал и его предложение) } \\
\text { работников на сегмен- } \\
\text { ты, на которые ориен- } \\
\text { тируется работодатель в } \\
\text { своих взаимоотношени- } \\
\text { ях с рынком труда }\end{array}$ & $\begin{array}{l}\text { Возможность устано- } \\
\text { вить целевые груп- } \\
\text { пы персонала при } \\
\text { регулировании рынка } \\
\text { труда в части спроса и } \\
\text { предложения рабочей } \\
\text { силы }\end{array}$ & $\begin{array}{l}\text { Возможность использо- } \\
\text { вать методы факторного и } \\
\text { кластерного анализа для вы- } \\
\text { явления критериев сегмен- } \\
\text { тирования и формирования } \\
\text { самих сегментов }\end{array}$ \\
\hline $\begin{array}{l}\text { Управленче- } \\
\text { ский (стра- } \\
\text { тегический } \\
\text { менеджмент, } \\
\text { управление } \\
\text { кадровым } \\
\text { составом, ан- } \\
\text { тикризисный } \\
\text { менеджмент) }\end{array}$ & $\begin{array}{l}\text { Деление персонала на } \\
\text { сегменты для принятия } \\
\text { решений о планирова- } \\
\text { нии, отборе, развитии, } \\
\text { удержании и оптими- } \\
\text { зации численности и } \\
\text { составе персонала в } \\
\text { стратегических или } \\
\text { антикризисных целях }\end{array}$ & $\begin{array}{l}\text { Возможность учесть } \\
\text { разные относитель- } \\
\text { но устойчивые и } \\
\text { повторяющиеся у } \\
\text { многих сотрудников } \\
\text { характеристики для } \\
\text { принятия адресных, } \\
\text { дифференцированных } \\
\text { кадровых решений }\end{array}$ & $\begin{array}{l}\text { Возможность применять } \\
\text { имеющиеся принципы } \\
\text { сегментирования персонала } \\
\text { и уже используемые виды } \\
\text { сегментов для сегментного } \\
\text { структурирования кадрового } \\
\text { ядра }\end{array}$ \\
\hline
\end{tabular}

В научных публикациях имеются попытки использования маркетинга для кадровой работы в учреждении. Например, интерес для данного исследования представляет подход С. Шекшни [1]. Он предлагает взять за основу несколько инструментов маркетинга:

1. Сегментация. Главная идея инструмента - к разным клиентам нужно подходить по-разному, и в основе маркетинговых предложений должно лежать разделение клиентов на несколько однородных групп со сходными потребностями.

2. Использование Value proposition («ценностное предложение»). Смысл этого инструмента в том, что предложение, сформулированное для каждого сегмента, должно быть обращено к тем ценностям, которые наиболее распространены среди потребителей данного сегмента.

3. Обратная связь. Маркетинг разрабатывает различные продукты для различных сегментов в зависимости от выявленных потребностей. В процесс разработки маркетинг включает самих клиентов: выясняются их интересы и потребности.

4. Ценообразование - еще один традиционный инструмент маркетинга и управления клиентами.

5. Реклама. Это инструмент целевого воздействия на клиентов, формирования у них представления о компании и интереса к ее продуктам (услугам).

6. Материальная заинтересованность руководства. Как правило, доходы высшего руководства напрямую зависят от тех результатов, которые компания достигает на рынке.

Далее С. Шекшня предлагает адаптацию этих инструментов к управлению персоналом. Согласно принципу сегментации к сотрудникам компании необходимо относиться по-разному, так как не все сотрудники имеют одинаковую ценность для

\section{Baikal Research Journal}


компании. По аналогии с тем, что все клиенты важны для компании, но не все одинаково, а в зависимости от количества потребляемого ими продукта, есть сотрудники, которые для компании в несколько раз более ценны, чем другие. Поэтому следует разделить сотрудников на категории исходя из их ценности для компании, и для каждого сегмента разработать свою систему управления. С. Шекшня предлагает определенную сегментацию персонала, которую приведем далее, и делает вывод о том, что в каждой компании может быть разработана своя сегментация персонала. После проведения сегментации возникает задача сформулировать ценностное предложение для того, чтобы привлечь, сохранить и заставить производительно работать сотрудников каждого сегмента.

Наиболее близки к предмету нашего исследования подходы к сегментированию, выработанные в экономике труда, а именно в теории рынка труда, а также в управлении персоналом. Согласно некоторым трактовкам сегментирование рынка труда представляет собой процесс разбивки предложения рабочей силы и спроса на нее на группы (сегменты), одинаково реагирующие на один и тот же побудительный мотив занятости. В этом случае сегменты представляют собой целевые группы, на которые ориентируется работодатель в своих взаимоотношениях с рынком труда. Образуемые целевые группы должны быть по возможности однородны по своему внутреннему содержанию, но разнородны по внешнему составу.

В управлении персоналом под сегментированием понимается индивидуальный подход к сотрудникам на основе их личных склонностей и предпочтений. В литературе предлагается делить персонал на сегменты по следующим критериям: возраст, пол, стаж, специальность, состояние здоровья, местонахождение, функции в организации, обучаемость и т. д. Сегментирование позволяет специалистам отдела кадров вести более целенаправленные отбор и удержание наиболее ценных сотрудников, обучение, распределение льгот и бонусов, сокращение и прочие кадровые мероприятия [5;9-11].

Многие авторы публикаций, не используя напрямую термин «кадровое ядро», тем не менее, говорят о важности дифференцированного подхода к управлению персоналом, о необходимости построения системы управления персоналом, ориентированной на запросы разных групп персонала, например, групп кадрового резерва [12-15].

Отталкиваясь от проанализированных определений, сформулируем собственное определение сегментации кадрового ядра. Начнем с того, что сегментация кадрового ядра производится после сегментации всего персонала, это необходимо для того, чтобы первоначально выделить само кадровое ядро. Сегментация кадрового ядра это деление кадрового ядра на сегменты, объединенные определенными признаками, с дальнейшим изучением реакций и поведения сегментов в рамках стратегии развития организации, установления наиболее активной части кадрового ядра (целевых сегментов) с целью выработки дифференцированной программы кадровых мероприятий в отношении разных сегментов для максимального вовлечения в стратегическую деятельность организации. Основными результатами сегментации являются выделение целевых сегментов, разработка дифференцированной программы работы с сегментами кадрового ядра.

Тесно связан с сущностью сегментации вопрос о том, для чего она производится. Если говорить обобщенно по всем подходам к трактовке сегментирования, то, по мнению авторов работ, оно осуществляется для того, чтобы сделать что-либо (товар, услугу, процесс, или систему) максимально приближенными к различающимся потребностям, предпочтениям, ценностям и интересам, иным чертам представителей каждого сегмента, т. е. сделать различными те объекты, которые предназначены для различающихся сегментов из общей совокупности субъектов.

\section{Baikal Research Journal}

электронный научный журнал Байкальского государственного университета 
В соответствии со сказанным, сегментация кадрового ядра осуществляется для того, чтобы определить целевые сегменты, отличающиеся друг от друга набором определенных признаков, и разработать адресную, дифференцированную политику и программу формирования и работы с сегментами кадрового ядра. Необходимо приблизить базовые принципы и мероприятия к специфике сегментов кадрового ядра для того, чтобы они давали больший эффект за счет позитивного восприятия сегментами тех или иных стратегических инициатив учреждения.

Обратимся к важному вопросу о структуре кадрового ядра на базе сегментации. Сразу отметим, что деление на сегменты довольно условно и во многом зависит от специфики организации и ее стратегии. Значимым является при сегментировании и то, для чего осуществляется сегментирование, следовательно, какие критерии сегментирования следует избрать.

Для выделения кадрового ядра можно брать разные связанные друг с другом критерии сегментирования. На взгляд автора, для выделения кадрового ядра хорошо подходит критерий ценности сотрудников для компании и их вклада в успешность организации, в достижение ею стратегии. В этой связи типичной является следующая сегментация персонала $[1 ; 2]$.

Первый сегмент составляет ключевой персонал - это сотрудники, которые представляют наибольшую ценность для компании и вносят значительный вклад в ее успех. $К$ ним относятся топ-менеджеры, часть перспективных менеджеров среднего уровня, редкие высококвалифицированные специалисты, связанные с инновационно-креативной деятельностью. Данный сегмент особенно важен в условиях кризиса, его сохраняют, на него делают ставку в стратегии развития. Именно этот сегмент выступает кадровым ядром, состоящим из ключевого персонала. Оперируя терминологией маркетинга - это целевая группа. Именно на нее должны быть направлены многие кадровые мероприятия и через нее они осуществляются в отношении остальных сегментов персонала.

Второй сегмент образуют руководители низшего и, отчасти, среднего звена, а также перспективные высококвалифицированные специалисты, занимающие в компании весьма значимые позиции. Этот сегмент также необходимо отражать в планах удержания персонала, конечно, учитывая при этом ситуацию на рынке труда и возможности трудоустройства на других предприятиях сокращаемых работников. Из этого сегмента формируется, условно говоря, резерв на включение в кадровое ядро. Данный сегмент выступает часто поддержкой инициатив кадрового ядра. Именно с этой группой персонала наиболее тесно работает кадровое ядро.

Третий сегмент составляют профессионалы (в данном случае это работники, обладающие средними для рынка профессиональными компетенциями и создающие среднюю ценность). Обычно это квалифицированные работники массовых профессий, которых без особых усилий можно найти на рынке труда.

В четвертый сегмент входит вспомогательный персонал, вклад которого в создаваемые ценности сравнительно невысок: обычно это работники средней и низкой квалификации, которые в избытке имеются на рынке труда. Представители третьего и четвертого сегмента не входят в ядро, но они являются объектом влияния кадрового ядра.

Само кадровое ядро также неоднородно и требует сегментации. Повторим идею о том, что сегментация кадрового ядра может проводиться по разным критериям, признакам: месту сотрудника в организационной структуре, квалификационным показателям, демографическим показателям, психологическим параметрам, мотивационной структуре личности, поведенческим моделям в актуальных ситуациях, готовности и толерантности к риску, лояльности компании и прочим. Выбор критерия или совокупности критериев зависит от целей сегментирования.

\section{Baikal Research Journal}

электронный научный журнал Байкальского государственного университета 
В данном исследовании принципом установления критериев сегментирования выбрана ориентация на функции кадрового ядра и соответствующие требуемые для этих функций компетенции. Важнейшим критерием считаем такие элементы компетенций, как мотивацию, ценности, интересы, так как активность в качестве участника кадрового ядра во многом предопределена наличием высокой мотивации на оказание помощи организации и отдельным ее представителям, на соучастие в управлении, на инновационные предложения и т. д. Можно сказать, что мотивация - это сквозной критерий, который должен учитываться при сегментировании по любым другим критериям.

Важнейшими критериями для сегментирования ядра являются также следующие критерии, напрямую связанные с сущностью кадрового ядра:

- участие в разработке и реализации стратегии организации;

- участие в разработке и реализации инновационной политики организации;

- уровень ценности для компании с позиций обеспечения конкурентоспособности и устойчивого развития;

- уровень ценности работников с позиций принесения дохода;

- обладание лидерством и уровень результативности лидерства;

- степень командности и приверженности командным целям и методам работы;

- уровень соучастия в делах управления организацией;

- уровень самоорганизованности и самоуправляемости;

- степень участия в процессах формирования и передачи ключевых знаний в учреждении;

- уровень участия в проектах учреждения и т. д.

По всем названным критериям возможно сегментирование кадрового ядра, выбор критериев зависит от цели сегментирования. Автор предлагает типовые цели и примеры критериев сегментирования в соответствии с ними:

1. Использовать кадровое ядро для разработки и реализации инновационной политики, максимально вовлечь с помощью кадрового ядра персонал периферии в инновационную программу, снять барьеры к инновациям. В этом случае критериями сегментирования могут стать уровень инновационности мышления, степень развитости мотивации к изменениям, способность к трансформационному лидерству (поддерживающему и провоцирующему изменения), степень участия в ранее проводимых инновациях и использования инновационных моделей поведения и др. Эти критерии позволяют выделить такие сегменты в структуре кадрового ядра, как наиболее инновационно настроенные участники ядра, со средней степенью инновационности, с низким уровнем инновационности. Отметим, что последний сегмент не предполагает исключения его из кадрового ядра, так как возможно, что входящие в него сотрудники обладают ключевыми компетенциями члена кадрового ядра, иными, не инновационными, но также значимыми, например, способностью формировать позитивную корпоративную культуру или обучать и развивать других.

2. Формирование системы управления знаниями в учреждении, вовлечение персонала в эту систему. Критерии сегментирования кадрового ядра: включенность в кадровый резерв, способности и мотивация к передаче знаний другим, участие в образовательных программах в качестве лидеров или преподавателей, тренеров, участие в совещаниях, обсуждениях и проработке значимого опыта, его обобщения и хранения в виде документов, методик технологий и др. Могут быть выделены сегменты: группа кадрового ядра, формирующая политику и генеральную линию в области управления знаниями, связывающая управления знаниями со стратегией организацией; группа, моделирующая систему управления знаниями; группа, помогающая внедрить систему управления знаниями, транслирующая эту систему на уровень сотрудников периферии.

\section{Baikal Research Journal}

электронный научный журнал Байкальского государственного университета 
3. Вовлечение кадрового ядра в разработку и реализацию стратегии организации. Критериями в этом случае могут быть: знания и квалификации в области стратегического менеджмента, тип реакции на стратегию учреждения, интенсивность участия в стратегических совещаниях и сессиях по разработке стратегии и плана ее реализации, степень готовности участвовать в реализации стратегии, степень лояльности к организации и к стратегии, ценность выгод, получаемых от участия в разработке стратегии и прочие. Примерами кластеров могут быть: группа кадрового ядра, инициирующая разработку стратегии, задающая общие ее ориентиры; группа разработчиков стратегии; группа разработчиков способов достижения стратегии; группа, формирующая настрой у всего персонала на реализацию стратегии и иные сегменты.

Приведенные примеры целей и критериев сегментирования подводят к важному выводу о том, что участник кадрового ядра может обладать не всеми важными для функций кадрового ядра компетенциями. У него могут быть ярко выражены одни компетенции и совсем слабыми иные. В этой связи автор предлагает такой критерий сегментации, как обладание совокупностью компетенций для выполнения функций кадрового ядра. Согласно критерия можно выделить два сегмента:

- универсалы (межкомптентностная сегментация) - те, кто обладает разнообразными компетенциями и может выполнять множество функций кадрового ядра;

- профессионалы (узкокомпетентностная сегментация) - те, кто обладает ограниченными, но ценными и высоко выраженными компетенциями для выполнения каких-то отдельных функций кадрового ядра.

Подводя итог, отметим, что автором предложена теоретическая сегментация кадрового ядра, т. е. посредством теоретических гипотез и предположений. На практике необходимо проводить сегментацию персонала и отдельно кадрового ядра в каждой отдельно взятой организации, под конкретные цели и на определенный промежуток времени. Такая практическая сегментация является, на взгляд автора, частью процесса формирования кадрового ядра. Необходимо также сказать о том, что не существует универсальных технологий сегментирования. Следует каждый раз решать вопрос и о том, как именно это делать, так как зачастую качество сегментирования кадрового ядра будет определяться интуицией и способностями того, кто проводит сегментирование. Кроме того, сегментирование - это не разовый процесс. Происходят изменения в сегментах и в целях сегментирования, поэтому сегментирование в рамках формирования кадрового ядра - это повторяющаяся процедура, цикличный процесс.

\section{Список использованной литературы}

1. Шекшня С. В. Управление персоналом: в поисках адекватной парадигмы [Электронный ресурс] / С. В. Шекшня // Персонал. - 2000. — № 3. — Режим доступа : http://hrm.ru/ upravlenie-personalom-v-poiskakh-adekvatnojj-paradigmy.

2. Маханькова Т. П. Применение кластерного анализа в управлении персоналом [Электронный ресурс] / Т. П. Маханькова, В. Н. Смоглюков. - Режим доступа: http://www. rusnauka.com/NPM_2006/Economics/5_mahan_kova.doc.htm.

3. Экономика и управление персоналом : энцикл. словарь / под ред. С. И. Сотниковой. Новосибирск : Новосиб. гос. ун-т экономики и упр., 2012. -468 с.

4. Лямин Г. В. Функции кадрового ядра персонала в условиях стратегического развития медицинского учреждения / Г. В. Лямин // Актуальные вопросы экономических наук : материалы XLVII Междунар. науч.-практ. конф. / под общ. ред. С. С. Чернова. - Новосибирск : Изд-во Центра развития науч. сотрудничества, $2015 .-300$ с.

5. Куликовская Л. Удержание ключевых сотрудников [Электронный ресурс] / Л. Куликовская // HR-эксперт. - Режим доступа : http://hrsovet.rabota.ua/uderzhanie-klyuchevyihsotrudnikov/.

6. Зеркалий Н. Г. Разработка эффективных программ внутриорганизационного маркетинга : автореф. дис. ... канд. экон. наук : 08.00.05 / Н. Г. Зеркалий. - Омск, 2011. - 24 с.

\section{Baikal Research Journal}

электронный научный журнал Байкальского государственного университета 
7. Демьяненко В. Ключевые сотрудники на пути развития организации [Электронный ресурс] / В. Демьяненко // Корпоративный менеджмент. - Режим доступа : http://www.cfin. $\mathrm{ru} /$ anticrisis/methodical_material/consultants/employee_adapt.shtml.

8. Фролова Н. Д. Кластерный подход как технология управления региональным экономическим развитием [Электронный ресурс] / Н. Д. Фролова. - Режим доступа: http://www. be5.biz/ekonomika1/r2012/3706.htm.

9. Уиддет С. Руководство по компетенциям : пер. с англ. / С. Уиддет, С. Холлифорд. M. : Нippo, 2008. - 240 c.

10. Мотивация персонала в современной организации : учеб. пособие / под общ. ред. С. Ю. Трапицына. - СПб. : Кн. Дом, 2007. - 240 с.

11. Лебедева О. И. Инновационные технологии управления человеческими ресурсами. Управление корпоративной компетенцией [Электронный ресурс] // О. И. Лебедева. - Режим доступа : http://gr.neftegaz.ru/ru/content/science/463.html.

12. Бахтаирова Е. А. Проблемы правового регулирования формирования и использования кадрового резерва на государственной гражданской службе / Е. А. Бахтаирова. - Иркутск : Изд-во БГУЭП, 2015. - 123 с.

13. Грачева Ю. И. Методика подбора и оценки конкурентоспособного работника на вакантную должность / Ю. И. Грачева // Известия Иркутской государственной экономической академии. - 2009. - № 3 (65). - С. 111-114.

14. Гусева Н. И. Новый подход управления, основанный на вовлечении сотрудников в управление компанией: миф или реальность? / Н. И. Гусева, В. А. Морыженков // Известия Иркутской государственной экономической академии. - 2015. - Т. 25, № 3. C. 426-434. - DOI : 10.17150/1993-3541.2015.25(3).426-434.

15. Солодова Н. Г. Особенности кадрового аудита при антикризисном управлении / Н. Г. Солодова, Л. В. Клейменова // Известия Иркутской государственной экономической академии. - 2011. - № 6 (80). - С. 104-108.

\section{References}

1. Shekshnya S. V. Personnel management: in search for adequate paradigm. Personal $=$ Per sonnel, 2000, no. 3. Available at: http://hrm.ru/upravlenie-personalom-v-poiskakh-adekvatnojj-paradigmy. (In Russian).

2. Makhan'kova T. P., Smoglyukov V. N. Primenenie klasternogo analiza $v$ upravlenii personalom [Use of cluster analysis in personnel management]. Available at: http://www.rusnauka. com/NPM_2006/Economics/5_mahan_kova.doc.htm.(In Russian).

3. Sotnikova S. I. (ed.). Ekonomika i upravlenie personalom. Entsiklopedicheskii slovar' [Economics and Personnel Management. Encyclopedic Dictionary]. Novosibirsk State University of Economics and Management Publ., 2012. 468 p.

4. Lyamin G. V. Functions of personnel HR-core in terms of strategic development of medical institution. In Chernov S. S. (ed.). Aktual'nye voprosy ekonomicheskikh nauk. Materialy XLVII Mezhdunarodnoi nauchno-prakticheskoi konferentsii [Topical Issues of Economic Sciences. Materials of the 47th International Research Conference]. Novosibirsk, Center for Scientific Cooperation Development Publ., 2015. 300 p.

5. Kulikovskaya L. Retention of key staffers. HR-Expert. Available at: http://hrsovet.rabota.ua/uderzhanie-klyuchevyih-sotrudnikov/. (In Russian).

6. Zerkalii N. G. Razrabotka effektivnykh programm vnutriorganiza-tsionnogo marketinga. Avtoref. Kand. Diss. [Development of effective programs of intra-organizational marketing. Cand. Diss. Thesis]. Omsk, 2011. 24 p.

7. Demyanenko V. Klyuchevye sotrudniki na puti razvitiya organizatsii. Korporativnyi menedzhment [Key personnel on the way of developing an organization. Corporate management]. Available at: http://www.cfin.ru/anticrisis/methodical_material/consultants/employee adapt.shtml.

8. Frolova N. D. Klasternyi podkhod kak tekhnologiya upravleniya regional'nym ekonomicheskim razvitiem [Cluster approach as a management technology for regional economic development]. Available at: http://www.be5.biz/ekonomika1/r2012/3706.htm. (In Russian).

9. Whiddett S., Holliforde S. The Competencies Handbook. London, Chartered Institute of Personnel \& Development, 1999. 224 p. (Russ. ed.: Whiddett S., Holliforde S. Rukovodstvo po kompetentsiyam. Moscow, Hippo Publ., 2008. 240 p.).

\section{Baikal Research Journal}

электронный научный журнал Байкальского государственного университета 
10. Trapitsyn S. Yu. (ed.). Motivatsiya personala $v$ sovremennoi organizatsii [Motivation of personnel in today's organization]. Saint Petersburg, Knizhnyi Dom Publ., 2007. 240 p.

11. Lebedeva O. I. Innovatsionnye tekhnologii upravleniya chelovecheskimi resursami. Upravlenie korporativnoi kompetentsiei [Innovative technologies of human resource management. Corporate competence management]. Available at: http://gr.neftegaz.ru/ru/content/science/463. html. (In Russian).

12. Bakhtairova E. A. Problemy pravovogo regulirovaniya formirovaniya i ispol'zovaniya kadrovogo rezerva na gosudarstvennoi grazhdanskoi sluzhbe [Problems of legal regulation of forming and using personnel reserve in public civil service]. Irkutsk, Baikal State University of Economics and Law Publ., 2015. 123 p.

13. Gracheva Yu. I. Personnel selection and estimation method. Izvestiya Irkutskoi gosudarstvennoi ekonomicheskoi akademii = Bulletin of Irkutsk State Academy of Economics, 2009, no. 3 (65), pp. 111-114. (In Russian).

14. Guseva N. I., Moryzhenkov V. A. Engagement management in Russia: Myths or reality? Izvestiya Irkutskoy gosudarstvennoy ekonomicheskoy akademii = Bulletin of Irkutsk State Academy of Economics y, 2015, vol. 25, no. 3, pp. 426-434. DOI: 10.17150/1993-3541.2015.25(3).426434. (In Russian).

15. Solodova N. G., Kleimenova L. V. Personnel audit in crisis management. Izvestiya Ir kutskoy gosudarstvennoy ekonomicheskoy akademii = Bulldtin of Irkutsk State Academy of Economics, 2011, no. 6 (80), pp. 104-108. (In Russian).

\section{Информация об авторе}

Лямин Геннадий Валерьевич - соискатель, Омский государственный университет им. Ф. М. Достоевского, 644077, г. Омск, просп. Мира, 55a, e-mail: lyaming@mail.ru.

\section{Author}

Gennady V. Lyamin - External PhD Student, F. M. Dostoevsky Omsk State University, 55a, Mira Av., 644077, Omsk, Russian Federation; e-mail: lyaming@mail.ru.

\section{Библиографическое описание статьи}

Лямин Г. В. Сегментный подход к кадровому ядру организации / Г. В. Лямин // Baikal Research Journal. — 2016. — T. 7, № 5. — DOI : 10.17150/2411-6262.2016.7(5).9.

\section{Reference to article}

Lyamin G. V. Segmental approach to HR-core of an organization. Baikal Research Journal, 2016, vol. 7, no. 5. DOI : 10.17150/2411-6262.2016.7(5).9. (In Russian).

\section{Baikal Research Journal}

